\title{
Exploring nurses' experience about facilitating factors in medication administration based on clinical judgment of nurses: A content analysis
}

\author{
Jamal Seidi ${ }^{1}$, Fatemeh Alhani ${ }^{2}$, Farasat Ardalan ${ }^{3}$
}

\author{
${ }^{1}$ Ph.D. of Nursing, Assistant Professor, Clinical Care Research Center, Kurdistan University of Medical Sciences, \\ Sanandaj, Iran \\ ${ }^{2}$ Ph.D. of Health Education, Associate Professor, Department of Nursing, Faculty of Medical Sciences, Tarbiat \\ Modares University, Tehran, Iran \\ ${ }^{3}$ M.Sc. of Nursing, Faculty Member, Department of Community Health Nursing, Faculty of Nursing and \\ Midwifery, Kurdistan University of Medical Sciences, Sanandaj, Iran
}

\section{Type of article: Original}

\begin{abstract}
Background: Clinical judgment of nurses to conduct medication orders is based on patient assessment, medication knowledge, observation, and interpretation of the data collected. This process is influenced by many factors.

Objective: This study aims to explore nurses' experience about facilitating factors in medication administration based on clinical judgment of nurses.

Methods: This qualitative study was part of an approved project research of the Iranian National Institute of Health Research, which was conducted in Kurdistan University of Medical Sciences in 2015. Based on purposive sampling of 18 participants, 26 open and semistructured interviews were conducted. Based on conventional content analysis method and using MAXQDA2010, coding and categorizing the data were applied. During the analysis, data collection continued until saturation.

Results: Analysis of the data led to the emergence of five themes, including the implementation of evidencebased medication orders, situational-based medication orders, medication orders in critical condition, educational interventions in medication orders, and supporting the nurses as facilitator of the implementation of medicinal orders based on clinical judgment of nurses.

Conclusion: In response to constraints such as the routines, clinical crisis and lack of evidence in medicinal orders, nurses used following ways to fix these barriers and facilitators. Combining evidence such as clinical guidelines, physician's views based on patients, and clinical conditions proved the best facilitator. It is recommended that, using these results, a perfect background for the proper administration of medication orders by nurses should be provided.
\end{abstract}

Keywords: Judgment, Nurse, Iran

\section{Introduction}

Based on clinical judgment, nurses can manage the correct use of medication by consultation and interprofessional care. Nurses as health care providers and health promotion providers have an important role in advising patients on how to use the medicine, and preventing or reporting the complications and side effects (1). In clinical judgment, with the existing condition, after deep thinking and reflective thinking based on observation, the nurse can collect the data purposefully by interview and examination. Based on the interpretation of data, the nurse performs information processing. After analysis, with rethinking and reflection on the subject, the nurse reaches a final

\section{Corresponding author:}

Farasat Ardalan, Department of Community Health Nursing, Faculty of Nursing and Midwifery, Kurdistan University of Medical Sciences, Sanandaj, Iran.

Tel: +98.9183718420, Fax: +98.8733660092, Email: ardalan.f@muk.ac.ir

Received: June 04, 2017, Accepted: September 24, 2017, Published: December 2017

iThenticate screening: September 28, 2017, English editing: October 27, 2017, Quality control: October 28, 2017

This article has been reviewed / commented by four experts

(C) 2017 The Authors. This is an open access article under the terms of the Creative Commons Attribution-NonCommercialNoDerivs License, which permits use and distribution in any medium, provided the original work is properly cited, the use is non-commercial and no modifications or adaptations are made. 
conclusion. In this process, the nurse uses skills such as experience, knowledge, evidence, critical thinking, reasoning, and intuition. This process will ultimately lead to clinical decision-making and nursing diagnosis (2). In order to carry out medical orders based on the observation, assessment of patient and environment and reference to evidences, the nurses collect data. Then, through interpretation, counseling, and deep thinking, they would arrive at a final conclusion to prescribe the appropriate medicine (3-5).

Literature points to various factors facilitating this procedure (6). One factor is concerned with how we make reference to evidences based on the clinical conditions (7). Other factors include conditions such as having the appropriate amount of time, an appropriate duty structure such as not having too many people in the clinic, and absence of work pressure and the possibility of attaining a high level of evidences just like empirical studies $(8,9)$. When there is no sufficient time to analyze medical orders or in the case of high work load and when there are few informational cues such as clinical or research evidence (10), the nurse will carry out or ignore medical orders based on his or her own experience and experts' previous knowledge, which is called "intuition" (11). Development of clinical judgment, might be affected by clinical experience, task difficulty and time pressure $(12,13)$. However, if the intuition is based upon personal experience or influenced by factors such as stress and work load, the result will be the wrong clinical judgment in undertaking medical orders (14). Another factor that impedes carrying out clinical-judgment-based medical orders is the unstructured clinical judgment or routine-base orientation (15). In such cases, the nurse makes judgments based upon her own personal experience regardless of the available evidences such as research results, instructions, guidelines and ideas of specialists, and clinical judgment (15). In a 2015 study, Seidi et al. realized that nurses and doctors were excessively dissatisfied with routine-based orientations and considered it a great problem in achieving structured clinical judgment based on scientific instructions, guidelines, and evidence (16). The only way out of this predicament is inter-occupational cooperation between doctor and nurse (12). In a 2013 study, Mc Millan and Emmerton revealed that nurses require inter-occupational cooperation between themselves and pharmacologists in order to carry out and prescribe medical orders (1). As the nurse achieves the resources and evidences and gains knowledge, he or she will not need to rush to carry out medical orders (17).

In a 2017 study, Parker-Tomlin et al. revealed that inter-professional healthcare providers require a cognitive continuum in clinical judgment to make the right decisions. This recognition is evidence-based according to existing conditions (10). Various quantitative studies have been conducted in regards to the standards of carrying out medical orders by nurses. However, determining their concerns about correctly carrying out medical orders based upon the clinical judgment of nurses is not possible by merely relying on quantitative studies, and it requires qualitative studies $(5,6)$. A review of the literature showed that nurses face various obstacles and facilitators to carry out medical orders based upon clinical judgment. Keeping in mind the fact that these barriers and facilitators of carrying out medical orders based upon the clinical judgment of nurses differ based on the type of culture and the social environment and clinical conditions of various communities, and no research has been conducted on this issue in Iran. The present research was conducted to determine the factors that facilitate carrying out of medical orders based upon nurses' clinical judgment. In relation with the present Iranian context, different cultural conditions, or the criticality of the clinical and patient environment may affect the type of clinical judgment in implementing the nursing drug orders. Based on the experience of researchers in the existing context, nurses working in an intensive care unit (ICU) have more autonomy in clinical judgment in dealing with the implementation of drug orders. This autonomy is achieved based on the interaction and consultation between the doctor and the nurse. In relation to the present Iranian context, different cultural conditions or the criticality of the clinical and patient environment may affect the type of clinical judgment in implementing nursing drug orders. Based on the experience of researchers in the existing context, nurses working in the ICU have more autonomy in clinical judgment in dealing with the implementation of the drug orders. This autonomy is achieved based on the interaction and consultation between the doctor and the nurse.

\section{Material and Methods}

\subsection{Study design}

This is a qualitative research conducted in accordance with the principles of content analysis. The purpose of the content analysis is to describe a phenomenon based on the experiences and opinions of the people involved in the subject $(1,18)$. Therefore, this method was appropriately chosen to describe the implementation of drug orders based on proper clinical judgment in nursing. We can describe it as a conventional content analysis (19). This study was a part of research plan approved by Iranian Health Researches National Institute conducted Kurdistan Medical Sciences University in 2015. 


\subsection{Sampling method}

The inclusion criteria features at least three years of useful work experience, having rich experiences in the implementation of drug orders by nurses based on their clinical judgment, and having informed consent to participate in the study. The exclusion criteria were the participant withdrawal from participation at each stage of the study. The first person rich in the experience of clinical judgment training was purposefully. Twenty-six open and half-structured interviews were conducted with 18 participants. Field notes were also taken while the interviews were being conducted. The sampling was purposeful based on the inclusion criteria. The first key participant was selected having the most experience on the implementation of clinical trials based on clinical judgment. Other participants were chosen purposefully based on their information needs and memo of the previous interviews.

\subsection{Data collection and analysis}

Data collection continued until we achieved a state of data saturation. Selected and other participants were chosen based on data guide and information requirements. The interviews lasted 60 minutes and were conducted over one or two sessions. The interviews were conducted by making appointments and based upon their agreement and approval of participating in research in the Nursing and Midwifery College or in a hospital. After reviewing the literature and asking the idea of the experts in the field, the interview guide was moderated, and it was tested in two interviews. Then, one central question and several correlated questions were put forward. The first general question asked was "What is your experience concerning carrying out of the medical orders based upon the clinical judgment of nurses?" Then, further questions were asked in a half-structured fashion based upon the data guide. The interviews were recorded by some MP3 players and then transcribed using some computer software. The initial codes were prepared in Microsoft Office Word, and the list of the codes and their categories were prepared in MAXQDA2010 environment. Content analysis was conducted in three phases based on the pattern proposed by Graneheim and Lundman (19). During the preparation phase, the author was drowned in data; the literatures were studied many times so that certain interpretations were formed about them. If the author came up with any important ideas during the research and brainstorming, they would be jotted down. In the organization phase, the focus was on semantic units or the sentences and statements made by the participants in the form of sentences, paragraphs, and primary codes. The repetitive codes were discarded in order to reduce the volume of codes. Categories and subcategories were extracted through classifying and refining the codes, and, finally, the themes were extracted. Reporting phase began when we had a set of good concepts with which the final analysis and report were issued. Interviews continued until data saturation was achieved, i.e., no new concepts were achieved by repeating the interviews. To ensure data saturation, two additional interviews were also conducted. Finally, data analysis resulted in the formation of main concepts and themes of the research.

\subsection{Rigor}

To observe the rigor of research, criteria such as credibility, dependability, and conformability were studied (20-22). Various methods such as constant monitoring and observation, allocating sufficient time for data collection, establishing good relationships with participants, and conducting the interviews in the places selected by participants were used for data credibility. Member check and peer check were used for conformability. For dependability, integration of data from different interviews was conducted. As for dependability, the data were stored up to two years after the end of research, and it was accessible for both the participants and the supervisors.

\subsection{Ethical considerations}

This research project included the following moral observations: making the arrangements and gaining permission to enter research environment, explaining the facts about research purpose, interview method and participants' right to take part in the research or to withdraw from it, and participants' assurance about the confidentiality of their names and information. In accordance with the contract number $241 / \mathrm{M} / 91175$, an ethical license was given by Iranian Health Research National Institute in order to conduct the research.

\section{Results}

The participants ranged from 26 to 47 years with their work history ranging from three to 27 years. One matron, two supervisors, two head nurses, two doctors, and 11 clinical nurses from different sections of the hospital were chosen (nine men and nine women). Data analysis yielded 620 primary codes, 16 subthemes, five themes, and one main theme (Table 1). 
Table 1. Examples of coding, subcategories, subthemes, and main themes

\begin{tabular}{|c|c|c|c|}
\hline Main theme & Themes & Subthemes & Example for codes \\
\hline \multirow[t]{15}{*}{$\begin{array}{l}\text { Factors facilitating } \\
\text { carrying out medical } \\
\text { orders based upon } \\
\text { clinical judgment }\end{array}$} & \multirow[t]{6}{*}{$\begin{array}{l}\text { Carrying out } \\
\text { evidence-based } \\
\text { medical orders }\end{array}$} & $\begin{array}{l}\text { Carrying out medical } \\
\text { orders appropriate } \\
\text { according to clinical } \\
\text { documents }\end{array}$ & $\begin{array}{l}\text { Carrying out medical orders appropriate } \\
\text { according to patient's history, nursing } \\
\text { reports and clinical examination results }\end{array}$ \\
\hline & & $\begin{array}{l}\text { Carrying out medical } \\
\text { orders appropriate } \\
\text { according to para-clinical } \\
\text { orders }\end{array}$ & $\begin{array}{l}\text { Carrying out medical orders appropriate } \\
\text { according to the reports issued by } \\
\text { laboratory, radiology and imaging }\end{array}$ \\
\hline & & $\begin{array}{l}\text { Carrying out medical } \\
\text { orders according to the } \\
\text { experiences and ideas of } \\
\text { specialists }\end{array}$ & $\begin{array}{l}\text { Carrying out medical orders in line with } \\
\text { the experiences and ideas of doctors, } \\
\text { nurses and clinical experts }\end{array}$ \\
\hline & & $\begin{array}{l}\text { Carrying out medical } \\
\text { orders in accordance with } \\
\text { the results of scientific and } \\
\text { research studies }\end{array}$ & $\begin{array}{l}\text { Carrying out the medical orders in line } \\
\text { with the research results, references and } \\
\text { credible texts }\end{array}$ \\
\hline & & $\begin{array}{l}\text { Carrying out medical } \\
\text { orders in accordance with } \\
\text { clinical guidelines }\end{array}$ & $\begin{array}{l}\text { Carrying out the medical orders in line } \\
\text { with clinical guidelines, instructions and } \\
\text { organizational policies }\end{array}$ \\
\hline & & $\begin{array}{l}\text { Carrying out medical } \\
\text { orders according to the } \\
\text { standards }\end{array}$ & $\begin{array}{l}\text { Carrying out medical orders in accordance } \\
\text { with standards of medicine prescription } \\
\text { and nursing care }\end{array}$ \\
\hline & \multirow[t]{2}{*}{$\begin{array}{l}\text { Carrying out } \\
\text { situation-based } \\
\text { orders }\end{array}$} & $\begin{array}{l}\text { Carrying out medical } \\
\text { orders according to } \\
\text { patient's clinical status }\end{array}$ & $\begin{array}{l}\text { Carrying out medical orders based on the } \\
\text { signs and symptoms of medical side } \\
\text { effects in the patient - carrying out } \\
\text { medical orders based on vital } \\
\text { interventions to save the patient }\end{array}$ \\
\hline & & $\begin{array}{l}\text { Carrying out medical } \\
\text { orders based on matching } \\
\text { with evidence }\end{array}$ & $\begin{array}{l}\text { Matching the validity of medical orders } \\
\text { with credible evidences - matching } \\
\text { medical side effects with credible } \\
\text { evidences }\end{array}$ \\
\hline & \multirow{2}{*}{$\begin{array}{l}\text { Educational } \\
\text { interventions for } \\
\text { medicine } \\
\text { prescription }\end{array}$} & Pharmacology & $\begin{array}{l}\text { Clinical conferences on pharmacology - } \\
\text { reporting medical side effects - nursing } \\
\text { care workshops for medicine prescription }\end{array}$ \\
\hline & & $\begin{array}{l}\text { How to utilize evidences in } \\
\text { prescribing medicines }\end{array}$ & $\begin{array}{l}\text { Evidence-based clinical conferences on } \\
\text { medicine prescription - evidence-based } \\
\text { nursing care workshops }\end{array}$ \\
\hline & \multirow[t]{3}{*}{$\begin{array}{l}\text { Supporting nurses } \\
\text { to carry out } \\
\text { medical orders }\end{array}$} & $\begin{array}{l}\text { Doctor's support for nurses } \\
\text { to carry out medical orders }\end{array}$ & $\begin{array}{l}\text { Doctors' supervision on carrying out } \\
\text { medical orders - doctor's aid to } \\
\text { inexperienced nurses to carry out medical } \\
\text { orders }\end{array}$ \\
\hline & & $\begin{array}{l}\text { Nurses' support for nurses } \\
\text { to carry out medical orders }\end{array}$ & $\begin{array}{l}\text { Nurses' supervision on carrying out } \\
\text { medical orders - nurses' aid to } \\
\text { inexperienced nurses to carry out medical } \\
\text { orders }\end{array}$ \\
\hline & & $\begin{array}{l}\text { Managers' support for } \\
\text { nurses to carry out medical } \\
\text { orders }\end{array}$ & $\begin{array}{l}\text { Providing the clinic with the manpower it } \\
\text { requires - providing the equipment to } \\
\text { prescribe medicine - providing the } \\
\text { required evidence needed to carry out } \\
\text { medical orders }\end{array}$ \\
\hline & \multirow[t]{2}{*}{$\begin{array}{l}\text { Carrying out } \\
\text { medical orders in } \\
\text { cases of emergency }\end{array}$} & $\begin{array}{l}\text { Carrying out medical } \\
\text { orders when there is a state } \\
\text { of emergency in the clinic }\end{array}$ & $\begin{array}{l}\text { Carrying out the orders in the emergency } \\
\text { service, ICU, and CCU }\end{array}$ \\
\hline & & $\begin{array}{l}\text { Carrying out medical } \\
\text { orders when the patient is } \\
\text { in a critical state }\end{array}$ & $\begin{array}{l}\text { Carrying out the orders for patient's } \\
\text { recovery, when dangerous side effects are } \\
\text { observed and during patient triage }\end{array}$ \\
\hline
\end{tabular}




\subsection{Carrying out evidence-based medical orders}

In response to barriers such as routine-based and duty-based orientations, the nurses resorted to their intuition in carrying out the medical orders, but a different kind of intuition was used. These intuitions included clinical and para-clinical evidences, specialists' experiences and ideas, results of scientific and research studies, standards and clinical guidelines. Nurses resorted to clinical evidences such as patient's history, nursing reports, and results of clinical examinations while carrying out medical orders. A nurse with six years' work experience in ICU stated that "As I was reading patient's history, I realized that he was allergic to penicillin, but the medical orders had prescribed cephalosporin injection. I informed the doctor about it, and he changed the medicine." The nurses used to use paraclinical documentations such as laboratory, radiology, and imaging reports while carrying out the medical orders. A nurse with 14 years' experience in emergency department stated, "The patient had potassium chloride infusion. I realized that the potassium level of blood is on the rise in laboratory reports. Immediately, I stopped drug infusion and informed doctor about it." The nurses used the experience and ideas of doctors, nurses, and clinical experts in carrying out the medical orders. One of the nurses in the emergency department with five years of work experience stated, "In infusion of Remifentanil for the patient, I noticed arrhythmia (PVC). I informed the doctor about it. According to his experience, this arrhythmia was caused by the preservative material used in the drug produced by [redacted] factory. It was then replaced by sufentanil produced by [redacted] factory and the problem of arrhythmia was resolved." Nurses used the researches in different levels, credible references, and texts while carrying out the medical orders. A nurse specialist with 20 years of work experience stated, "In a scientific conference with a pharmacist on comparing furosemide and acetazolamide, I did not accept doctor's judgment and presented him with evidences." Nurses used clinical guidelines and instructions and organizational policies while carrying out the medical orders. One of the nurses in the ICU with 10 years of work experience stated, "I use the clinical guideline for prescribing medicines in the ICU. These guidelines are really useful in prescribing and preventing medical side effects, but it is the doctors' ideas that constitute the final decision to carry out medical orders." Nurses used standards while carrying out the medical orders. Head nurse of the ICU with 15 years of work experience stated that "We have learnt to resort to the sixth law of standard including the correct name, correct dose, correct shape, correct use, correct prescription and correct documentation of the medicine while judging a medical order."

\subsection{Carrying out situation-based medical orders}

It happens sometimes that the clinical situation or condition of a patient suddenly changes, and the nurse needs to adjust the medical orders based on an intuition different from her previous intuitions. In such conditions, medical orders are carried out based on the clinical conditions of the patient or by matching them with intuition. One of the nurses in the surgical department, who had seven years of work experience, stated, "In examining a patient under a ventilator, I realized that he was in a state of convulsion. The inspections indicated a kidney failure for which he had received morphine. The morphine was quickly discarded and sufentanil infusion started." In the cases where medical orders or occurrence of medical side effects could be questioned, the nurses needed to match them with credible evidences. One of the nurses in the surgical department who had 14 years of work experience stated that "I resorted to the specialists' experiences while carrying out medical orders. If I ever doubted the validity of orders, I would resort to clinical guidelines and try to match them with patient's condition."

\subsection{Educational interventions of medicine prescription}

Some nurses had not updated their knowledge in terms of pharmacology and required training; thus, educational interventions such as clinical conferences of pharmacology, medical side effects reports, and medicine prescription and evidence utilization in nursing care workshops were held for them. Head nurse of the postpartum ward with 15 years of work experience stated, "I have a clinical conference about nursing cares in prescribing the common medicines in the unit on a weekly basis which is quite useful and good."

\subsection{Supporting the nurses to carry out medical orders}

According to law, the nurses required support from doctors and administrators to carry out medical orders as doctors are in charge of prescribing medicines, and nurses are responsible to carry out the orders. One of the nurses in the $\mathrm{CCU}$, who had 21 years of work experience, stated, "I had to carry out the order issued by doctor on the telephone by the testimony of one of my coworkers. The patient's family later filed a complaint due to the medical side effects. Doctor's support for us and accepting the charge of the decision spared us from any problems." Concerning the supervision of head nurses on carrying out the medical orders, the nursing manager said, "We train nurses how to react in the face of medical errors. This will prevent medical side effects and paves the way to advocate the nurse." Concerning the organizational managers' support for nurses to carry out medical orders, a manager said, "We had a joint meeting with nurses and it turned out that issues such as manpower, medical equipment, and clinical guidance 
shortage were the main issue the nurses were complaining about. We are sure that resolving these issues reduces medical errors and clinical death toll."

\subsection{Carrying out medical orders in critical conditions}

Carrying out medical orders issued to the nurses is more dependent upon the intuition gained through experience than intuition-based reasoning because they have no time for reasoning. One of the nurses in the urgent department who had seven years of work experience stated, "Cases of emergency influence our clinical judgment in carrying out medical orders as we had no time for discussion and we simply had to follow doctor's orders. However, when I was in the internal diseases unit, I had sufficient time. In this condition, we could easily hold conferences and discussions over medical orders using evidence such as papers and books." An important issue in triage, recovery, and unpredicted incidents is utilization of clinical guidelines as the most credible evidences. Available and up-to-date guidelines are really helpful in carrying out medical orders. One of the nurses in the ICU, who had seven years of work experience, stated, "In ICU, we have a clinical guideline to prescribe sufentanil for the patients under ventilator. We use the guideline and match it with doctors' orders."

\section{Discussion}

In the present study, the nurses resorted to intuition to carry out medical orders. However, the type of the evidence used was different. A 2013 study by Woien and Bjork showed that nurses who resorted to standard guidelines had a better performance (6). In a 2013 study, Vugt et al. arrived at the conclusion that para-clinical and clinical results were a kind of evidence which supported clinical judgment. For example, clinical judgment using radiology cliché of chest could be used to diagnose causes of cough (23). The variety of utilizing evidences in carrying out the orders was much similar to previous researches and studies $(16,24)$, but there was an inclination to use low-level evidences such as the ideas and experience of experts and doctors rather than clinical guidelines. In some cases in our research, carrying out medical orders followed a situation-based fashion. A 2013 study by Seidi et al. showed that an appropriate combination of the evidence based on patient's status and environment can enhance the clinical judgment of nurses (12). Hallin et al. arrived at the conclusion that those students capable of mixing various skills based upon patient's status could have a better clinical judgment (25). A 2012 study by Cranley et al. showed that the inappropriate combination of clinical knowledge and experience with temporal and situational conditions is the main obstacle to assessment of possibilities by nurse (26). In a 2011 study, Howland concluded that recognizing the medical side effects based upon assessment of dangers can be effective in preventing medical reactions (27). It was observed in the present research that some nurses, despite having an appropriate command in pharmacology, carried out medical orders according to inexperienced doctors' views and ideas, which resulted in medical side effects. However, the majority of nurses carried out medical orders (just like the previous studies) according to patient's status and valid evidences. Our results showed that some nurses had not updated their knowledge of pharmacology and required training.

In a 2008 study, Tanner pointed to the fact that improving clinical judgment based upon nurses' intuition required training (28). In a 2015 study, Seidi et al. revealed that nurses use various methods such as clinical conferences, workshops, and case reports to improve their clinical judgments (12). A 2013 study by Foster et al. showed that inservice training could enhance the clinical judgment of clinical nurses significantly (29). A 2012 study by Overbosch et al. showed that nurses needed to be properly trained before they could start prescribing medicines. In the present study, the nurses utilized educational intervention (like previous researches) to improve their clinical judgment in order to carry out medical orders (30). However, the only difference with the previous researches was inappropriate clinical background, as the units were crowded and the nurses were busy. In our research, nurses required support from doctors, experienced nurses, and managers to carry out medical orders. In a 2009 study, Benner revealed that experienced and professional nurses need to help inexperienced and new nurses so that they may grow professional too (31). In a 2014 study, Seidi et al. concluded that, when the way is paved to provide professional support to nurses, their attempts to develop their clinical judgment will be quite fruitful (5).

By reducing job stress and creating a safe working environment, clinical administration professionalization of nurses in clinical judgment (32). Similar to previous researches, doctors and colleagues were supportive of nurses' clinical judgment in carrying out medical orders. However, there were no clinical rules and guidelines to support nurses in carrying out the medical orders. As shown in our research, emergency conditions of the patient in a hospital leave no time to use intuition to carry out medical orders. The most effective and the best intuitions in such a situation is clinical guidelines. If those guidelines were not available, the nurses would then need to resort to doctors' ideas and experiences to carry out medical orders. The most appropriate condition for clinical judgment is situational 
utilization of evidences such as guidelines in accordance with the systematic examination of patient and ideas of colleagues (33). The results of our research were in line with the previous researches and showed that carrying out medical orders in the cases of emergency is a mixture of resorting to clinical guidelines and specialists' ideas, which are the most appropriate facilitators. In a cognitive continuum on nurses' clinical judgment. In a 2008 study, Standing points to the fact that a mixture of utilizing intuition in clinical judgment depends on clinical conditions, having sufficient time, and enough information (8). This view is in line with results of our research. Considering the nature of the qualitative study, one of the limitations of this study is that the probability of transferability to other communities may be low. From other limitations one can think of, clinical researcher records and experiences could affect interpretation of the data. With the argument that the researcher's presence in a natural environment is completely uncontrollable, so we attempted to use the researcher's experiences to facilitate understanding of the problem instead of having influence on the data.

\section{Conclusions}

As the results indicate, nurses use various strategies to deal with the obstacles to making clinical judgments in carrying out medical orders. The most important obstacles to achieving this goal were routine-based orientations, unavailability of proper and valid evidences, critical conditions of the hospital of patients, lack of laws supporting nurses, and the inappropriate educational interventions to utilize clinical judgment in carrying out medical orders. As the results indicate, the best facilitating factor for clinical judgment of nurses in carrying out medical orders was a mixture of intuitions based upon patient's condition and clinic. Providing credible and up-to-date clinical guidelines in a clinic and matching them with ideas of specialists and patients' conditions is a good strategy. Educating nurses about rules and standards to carry out medical orders is another facilitation factor that can enhance their clinical judgment. It is recommended to use the results of this research to pave the way for the correct implementation of medical orders by nurses in clinics.

\section{Acknowledgments:}

In accordance with the contract number 241/M/91175, the present research has been conducted with the financial support of Iranian Health Research National Institute, Tehran University of Medical Sciences and with cooperation of professors from Kurdistan University of Medical Sciences, Tarbiat Modarres University and Medical Sciences University of Tehran. The authors wish to thank Iranian Health Research National Institute for its financial support of this project. We would also like to thank the research and technology deputy of Kurdistan University of Medical Sciences that provided us with a place to conduct our research. This research was supported by the research cluster grant (93/132) from Kurdistan University of Medical Sciences, Sanandaj, Iran. The authors received no financial support for the authorship and/or publication of this article.

\section{Conflict of Interest:}

There is no conflict of interest to be declared.

\section{Authors' contributions:}

All authors contributed to this project and article equally. All authors read and approved the final manuscript.

\section{References:}

1) McMillan SS, Emmerton L. Nurse practitioners: an insight into their integration into Australian community pharmacies. Research in social \& administrative pharmacy: RSAP. 2013; 9(6): 975-80. PMID: 23062783.

2) Seidi J, Alhani F, Salsali M. Clinical Judgment in Nursing: a Concept Analysis using Rodgers' Evolutionary Method. Hayat. 2014; 20(2): 1-13.

3) Courtenay M. Nurse prescribing and community practitioners. J Fam Health Care. 2010; 20(3): 78-80. PMID: 20695351.

4) Offredy M, Kendall S, Goodman C. The use of cognitive continuum theory and patient scenarios to explore nurse prescribers' pharmacological knowledge and decision-making. Int J Nurs Stud. 2008; 45(6): 855-68. doi: 10.1016/j.ijnurstu.2007.01.014. PMID: 17362959.

5) Seidi J, Alhani F, Salsali M. Professional support as a facilitator to the development of Iranian nurses' clinical judgment: A content analysis. Iran J Nurs Midwifery Res. 2014; 19(7 Suppl 1): S13-8. PMID: 25949247, PMCID: PMC4402993.

6) Woien H, Bjork IT. Intensive care pain treatment and sedation: nurses' experiences of the conflict between clinical judgement and standardised care: an explorative study. Intensive \& critical care nursing. 2013; 29(3): 128-36. doi: 10.1016/j.iccn.2012.11.003. PMID: 23219402. 
7) Scott PJ, Rigby M, Ammenwerth E, Brender McNair J, Georgiou A, Hypponen H, et al. Evaluation Considerations for Secondary Uses of Clinical Data: Principles for an Evidence-based Approach to Policy and Implementation of Secondary Analysis. Yearb Med Inform. 2017; 26(1). doi: 10.15265/IY-2017-010. PMID: 28480477.

8) Standing M. Clinical judgement and decision-making in nursing-nine modes of practice in a revised cognitive continuum. J Adv Nurs. 2008; 62(1): 124-34. doi: 10.1111/j.1365-2648.2007.04583.x. PMID: 18352971.

9) Tiffen J, Corbridge SJ, Slimmer L. Enhancing clinical decision making: development of a contiguous definition and conceptual framework. Journal of professional nursing. 2014; 30(5): 399-405. PMID: 25223288 .

10) Parker-Tomlin M, Boschen M, Morrissey S, Glendon I. Cognitive continuum theory in interprofessional healthcare: A critical analysis. J Interprof Care. 2017; 31(4): 446-54. doi: 10.1080/13561820.2017.1301899. PMID: 28388258.

11) Pretz JE, Folse VN. Nursing experience and preference for intuition in decision making. J Clin Nurs. 2011; 20(19-20): 2878-89. doi: 10.1111/j.1365-2702.2011.03705.x. PMID: 21592247.

12) Seidi J, Alhani F, Salsali M. Nurses' Clinical Judgment Development: A Qualitative Research in Iran. Iranian Red Crescent medical journal. 2015; 17(9): e20596. doi: 10.5812/ircmj.20596. PMID: 26473075 PMCID: PMC4601210.

13) Yang $H$, Thompson $C$, Bland $M$. The effect of clinical experience, judgment task difficulty and time pressure on nurses' confidence calibration in a high fidelity clinical simulation. BMC medical informatics and decision making. 2012; 12: 113. PMID: 23034048.

14) Farhadbeigi P, Bagherian F, Banaraki AK. The effect of stress on accuracy and speed of judgment. Procedia - Social and Behavioral Sciences. 2012; 32(0): 49-52. doi: 10.1016/j.sbspro.2012.01.009.

15) Falzer PR. Valuing structured professional judgment: predictive validity, decision-making, and the clinicalactuarial conflict. Behavioral sciences \& the law. 2013; 31(1): 40-54. PMID: 23339121.

16) Seidi J, Alhani F, Salsali M, Kazemnejad A. 66: Exploring the application of evidence in the iranian nurses' clinical judgment and decision making: a hybrid qualitative study. BMJ. 2017; 7(Suppl 1). doi: 10.1136/bmjopen-2016-015415.66.

17) Carey N, Courtenay M. An exploration of the continuing professional development needs of nurse independent prescribers and nurse supplementary prescribers who prescribe medicines for patients with diabetes. Journal of clinical nursing. 2010; 19(1-2): 208-16. doi: 10.1111/j.1365-2702.2009.02943.x. PMID: 20500258.

18) Hsieh HF, Shannon SE. Three approaches to qualitative content analysis. Qualitative health research. 2005; 15(9): 1277-88. doi: 10.1177/1049732305276687. PMID: 16204405.

19) Gerdeman JL, Lux K, Jacko J. Using concept mapping to build clinical judgment skills. Nurse Educ Pract. 2013; 13(1): 11-7. doi: 10.1016/j.nepr.2012.05.009. PMID: 22698820.

20) Thomas E, Magilvy JK. Qualitative Rigor or Research Validity in Qualitative Research. Journal for Specialists in Pediatric Nursing. 2011; 16(2): 151-5. doi: 10.1111/j.1744-6155.2011.00283.x. PMID: 21439005.

21) Zamanzadeh V, Ahmadi F, Behshid M, Irajpoor A, Zakeri-Milani P. Osteoarthritis Patients' Experiences of Pharmacotherapy for Pain Management in Iran: A Qualitative Study. Drug Res. 2017; 67(6): 327-36. doi: 10.1055/s-0042-121420. PMID: 28351081.

22) Dainty KN. Reaching Beyond Doing a Survey and a Few Interviews: The Importance of Maintaining Rigor \& Validity in Prehospital Qualitative Research. Prehosp Emerg Care. 2017: 21(4): 537-8. doi: 10.1080/10903127.2017.1282563. PMID: 28509603.

23) van Vugt SF, Verheij TJ, de Jong PA, Butler CC, Hood K, Coenen S, et al. Diagnosing pneumonia in patients with acute cough: clinical judgment compared to chest radiography. The European respiratory journal. 2013; 42(4): 1076-82. doi: 10.1183/09031936.00111012. PMID: 23349450.

24) Seidi J, Alhani F, Salsali M, Kazemnejad A. 155: A study of correlation between the use of evidence in iranian nurses' clinical judgment and decision making with some related factors in 2015. BMJ. 2017; 7(Suppl 1). doi: 10.1136/bmjopen-2016-015415.155.

25) Hallin K, Backstrom B, Haggstrom M, Kristiansen L. High-fidelity simulation: Assessment of student nurses' team achievements of clinical judgment. Nurse education in practice. 2016; 19: 12-8. PMID: 27428686 . 
26) Cranley LA, Doran DM, Tourangeau AE, Kushniruk A, Nagle L. Recognizing and responding to uncertainty: a grounded theory of nurses' uncertainty. Worldviews Evid Based Nurs. 2012; 9(3): 149-58. PMID: 22233501.

27) Howland RH. Understanding and assessing adverse drug reactions. Journal of psychosocial nursing and mental health services. 2011; 49(10): 13-5. doi: 10.3928/02793695-20110915-01. PMID: 21956791.

28) Tanner CA. Clinical judgment and evidence-based practice: toward pedagogies of integration. J Nurs Educ. 2008; 47(8): 335-6. PMID: 18751646.

29) Foster KN, Lewis M, Marshall A, Lewis P. Educating Australian registered nurses in comprehensive health assessment: a pilot study. J Contin Educ Nurs. 2013; 44(4): 155-62. PMID: 23387309.

30) Overbosch FW, Koeman SC, van den Hoek A, Sonder GJ. Dutch travel health nurses: prepared to prescribe? Journal of travel medicine. 2012; 19(6): 361-5. PMID: 23379706.

31) Benner P, Tanner CA, Chesla CA. Expertise in Nursing Practice Caring, Clinical Judgment \& Ethics. 2nd ed. New York: Springer Publishing Company, LLC; 2009.

32) Gray-Stanley JA, Muramatsu N, Heller T, Hughes S, Johnson TP, Ramirez-Valles J. Work stress and depression among direct support professionals: the role of work support and locus of control. J Intellect Disabil Res. 2010; 54(8): 749-61. PMID: 20633203, PMCID: PMC3674855.

33) Richter Sundberg L, Garvare R, Nystrom ME. Reaching beyond the review of research evidence: a qualitative study of decision making during the development of clinical practice guidelines for disease prevention in healthcare. BMC health services research. 2017; 17(1): 344. doi: 10.1186/s12913-017-22771. PMID: 28490325 , PMCID: PMC5426017. 